\title{
Mechanical properties of orthodontic wires made of super engineering plastic
}

\author{
Minami MAEKAWA ${ }^{1}$, Zuisei KANNO'1, Takahiro WADA², Toshio HONGO², Hisashi DOI², Takao HANAWA ${ }^{3}$, \\ Takashi $\mathrm{ONO}^{1}$ and Motohiro $\mathrm{UO}^{2}$ \\ ${ }^{1}$ Department of Orthodontic Science, Oral Health Sciences, Graduate School of Medical and Dental Sciences, Tokyo Medical and Dental University, \\ 1-5-45 Yushima, Bunkyo-ku, Tokyo 113-8549, Japan \\ 2 Department of Advanced Biomaterials, Oral Health Sciences, Graduate School of Medical and Dental Sciences, Tokyo Medical and Dental University, \\ 1-5-45 Yushima, Bunkyo-ku, Tokyo 113-8549, Japan \\ ${ }^{3}$ Department of Metals, Institute of Biomaterials and Bioengineering, Tokyo Medical and Dental University, 2-3-10 Kanda-Surugadai, Chiyoda-ku, \\ Tokyo 101-0062, Japan \\ Corresponding author, 1st: Zuisei KANNO; E-mail: z.kanno.orts@tmd.ac.jp, 2nd: Motohiro UO; E-mail: uo.abm@tmd.ac.jp
}

\begin{abstract}
Most orthodontic equipment is fabricated from alloys such as stainless steel, Co-Cr and Ni-Ti because of their excellent elastic properties. In recent years, increasing esthetic demands, metal allergy and interference of metals with magnetic resonance imaging have driven the development of non-metallic orthodontic materials. In this study, we assessed the feasibility of using three super engineering plastics (PEEK, PES and PVDF) as orthodontic wires. PES and PVDF demonstrated excellent esthetics, although PEEK showed the highest bending strength and creep resistance. PEEK and PVDF showed quite low water absorption. Because of recent developments in coloration of PEEK, we conclude that PEEK has many advantageous properties that make it a suitable candidate for use as an esthetic metal-free orthodontic wire.
\end{abstract}

Keywords: Orthodontic wire, Thermoplastic resin, Super engineering plastic, Esthetics, Metal-free

\section{INTRODUCTION}

Most orthodontic equipment is made of metal alloys such as stainless steel, cobalt-chromium (Co-Cr) and nickel-titanium (Ni-Ti) because of their excellent elastic properties ${ }^{1-4)}$. However, recent years have seen increasing demand for non-metallic orthodontic materials. This is largely a result of higher esthetics, but also complications such as metal allergy and interference with magnetic resonance imaging (MRI) ${ }^{5,6}$. Glass fiberreinforced plastic (GFRP) has been investigated as a potential alternative ${ }^{7,8)}$, and GFRP wires were found to have high flexural strength and good esthetic properties. However, they also exhibited considerable bending and distortion that caused disruption of the fiber/polymer interface and decreased their mechanical properties. As another alternative, coated orthodontic wires have recently become available. The surface modification of these wires provides improved esthetics; however, there are still problems with corrosion and metal allergy ${ }^{9,10)}$. Polyphenylene polymers have also been developed into transparent orthodontic wires that are able to deliver forces equivalent to beta-titanium and $\mathrm{Ni}$-Ti wires ${ }^{11}$. Polyphenylene wires have a smooth surface with consistent cross-sectional dimensions, high spring back, ductility, and high formability, which allows shape bending.

Various plastic materials have been developed for industrial use that provide superior mechanical and thermal properties compared with conventional plastics. These are known as "engineering plastics" and are widely used. Continuation of this development led to the creation of "super engineering plastics (SEPs)", which have even higher mechanical strength and improved thermal and chemical stability ${ }^{12,13)}$. These superior mechanical properties allow SEPs to be applied as alternatives to metallic orthodontic wires. Their superior thermal and chemical stability mean that toxicity is expected to be low $^{14-16)}$ and SEPs have already been used in various industrial and medical fields ${ }^{17,18)}$ so have wellestablished production and forming methods. In this study, we investigated three types of SEPs as the base materials for orthodontic wires: polyether ether ketone (PEEK), polyether sulfone (PES) and polyvinylidene difluoride (PVDF). These SEPs provide different mechanical, chemical and esthetic properties: PEEK has the highest mechanical strength (tensile and bending), while PES has been used successfully and safely as a denture base material with high mechanical strength and good esthetics among SEPs. PVDF is mechanically the strongest in the category of fluoroplastic, and has good esthetics and chemical stability. In this study, we estimated the feasibility of using these SEPs as orthodontic wires.

\section{MATERIALS AND METHODS}

\section{Materials}

PEEK, PES and PVDF plates (1.0 mm thickness; KDA Corporation, Tokyo, Japan) were cut using a dicing machine (PFG-500DXAL, Okamoto Machine Tool Works, Ltd., Annaka, Japan) into $20 \mathrm{~cm}$ lengths with cross sectional dimensions of $1.0 \times 1.0 \mathrm{~mm}$ square. The deviation in the cutting width was $\pm 0.01 \mathrm{~mm}$; therefore allowing cutting to be undertaken in parallel. Stainless steel (SS), Co-Cr, titanium-molybdenum (Ti-Mo) and Ni- 
Ti super-elastic wires $(0.40 \times 0.55 \mathrm{~mm})$ were also tested for comparison. The wires tested are shown in Table 1.

\section{Three-point bending test}

The flexural properties were estimated with the threepoint bending test using a universal testing machine (AG-IS 500 N, Shimadzu, Kyoto, Japan). Wire specimens were placed on two round metal jigs (5.0 $\mathrm{mm}$ in diameter) with a 14-mm span length and deflected by $2.0 \mathrm{~mm}$ (at $1 \mathrm{~mm} / \mathrm{min}$ ) with another round metal jig before returning to the original position. This experiment was conducted in an acrylic box maintained at $37^{\circ} \mathrm{C}$ by air heating. Five replicates of each material were tested. Maximum bending stress $(\sigma)$ and elastic modulus (E) were calculated from the following expression:

$$
\sigma=(3 \cdot \mathrm{P} \cdot \mathrm{l}) /\left(2 \cdot \mathrm{b} \cdot \mathrm{h}^{2}\right)
$$$$
\mathrm{E}=\left(\mathrm{l}^{2} \cdot \sigma\right) /(6 \cdot \mathrm{h} \cdot \delta),
$$

where $\mathrm{P}$ is the flexural load, $\mathrm{l}$ is the distance between the two jigs, $b$ and $h$ are the width and height, respectively, of the sample wires, and $\delta$ is the deflection (in $\mathrm{mm}$ ).

\section{Bending creep test}

The bending creep properties of PEEK, PES and PVDF wires were estimated under constant deflection conditions. Specimens were fixed in the same geometry as for the three-point bending test (2.0 $\mathrm{mm}$ deflection) and kept in distilled water (DW) at $37^{\circ} \mathrm{C}$ for various times ranging from 2 weeks to 1 month. Creep deformation was then estimated by measuring permanent deformation at the bending center. Four replicates of each material were tested.

\section{Water absorption test}

To estimate the water absorption of SEPs, disk shaped PEEK, PES and PVDF $(10 \times 10 \times 1.0 \mathrm{~mm})$ were polished with emery paper (\#2000) and immersed in DW at $37^{\circ} \mathrm{C}$ for 10 days. After immersion, the samples were gently wiped and dried in air overnight at room temperature. Then, their weight change after this period measured. For comparison with ordinary plastics, PMMA was treated with the same method. An accelerated water absorption test was also carried out by immersing SEPs in DW and autoclaving them at $121^{\circ} \mathrm{C}$ and at 2 atmospheric pressure for 10 days. Four replicates of each material were tested in both conditions.

\section{RESULTS}

\section{Esthetics}

Figure 1 shows the appearance of PEEK, PES and PVDF plates at $1.0 \mathrm{~mm}$ thickness. PEEK is opaque and beigecolored, while PES is transparent and slightly ambercolored in appearance. PVDF is translucent and white. All three types of plastic demonstrated good esthetics, but PES and PVDF had particularly good esthetic properties.

\section{Three-point bending test}

Figure 2a shows typical load-deflection curves of the wires tested. SS and Co-Cr wires had higher flexural loads and larger permanent deformations than the other metallic and SEP wires. Ni-Ti wire gave a characteristic load-deflection curve without permanent deformation. SEP wires tolerated similar loads to Ni-Ti wire and

Table 1 Commercial orthodontic wires tested in this study

\begin{tabular}{lccc}
\hline Common name & Abbreviation & Trade name & Manufacturer \\
\hline Stainless steel & SS & STANDARD RECT. WIRE & 3M Unitek, St. Paul, MN, USA \\
Co-Cr alloy & Co-Cr & SPRON510 Straight Wires & TOMY, Tokyo, Japan \\
Ti-Mo alloy & Ti-Mo & TMA LOW FRICT & ORMCO, Orange, CA, USA \\
Ni-Ti alloy & Ni-Ti & L\&H TITAN ARCH WIRE & TOMY, Tokyo, Japan \\
\hline
\end{tabular}

Trial orthodontic wires tested in this study

\begin{tabular}{|c|c|c|c|c|}
\hline Common name & Abbreviation & Manufacturer & $\begin{array}{l}\text { Upper: Relative thermal } \\
\text { index }\left({ }^{\circ} \mathrm{C}\right)^{19)} \\
\text { Lower: Load deflecting } \\
\text { temperature }\left({ }^{\circ} \mathrm{C}\right)^{20)}\end{array}$ & $\begin{array}{l}\text { Tensile strength } \\
(\mathrm{MPa})^{20)}\end{array}$ \\
\hline $\begin{array}{l}\text { Polyether ether } \\
\text { ketone }\end{array}$ & PEEK & $\begin{array}{c}\text { Kubopura Corporation, } \\
\text { Tokyo, Japan }\end{array}$ & $\begin{array}{l}250 \\
160\end{array}$ & 71-103 \\
\hline Polyether sulfone & PES & $\begin{array}{c}\text { Kubopura Corporation, } \\
\text { Tokyo, Japan }\end{array}$ & $\begin{array}{c}200 \\
201-203\end{array}$ & $68-95$ \\
\hline $\begin{array}{l}\text { Polyvinylidene } \\
\text { difluoride }\end{array}$ & PVDF & KDA, Tokyo, Japan & $\begin{array}{c}125 \\
84-118\end{array}$ & $25-50$ \\
\hline
\end{tabular}

Relative thermal index: Temperature to retain half of properties (mechanical, electrical, etc.) of polymers for long time Load deflecting temperature: Temperature at the polymer deforms under a specified load 
with negligible permanent deformation. Comparison of the applied load at $2.0 \mathrm{~mm}$ deflection is shown in Fig. 3 , which indicates the orthodontic forces exerted on

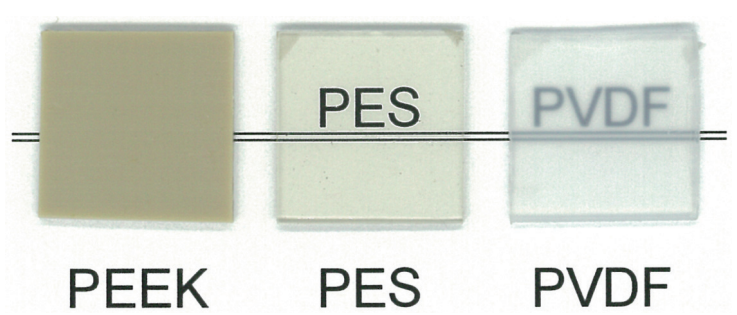

Fig. 1 Color characteristics of PEEK, PES and PVDF (1.0 $\mathrm{mm}$ in thickness).

(a)

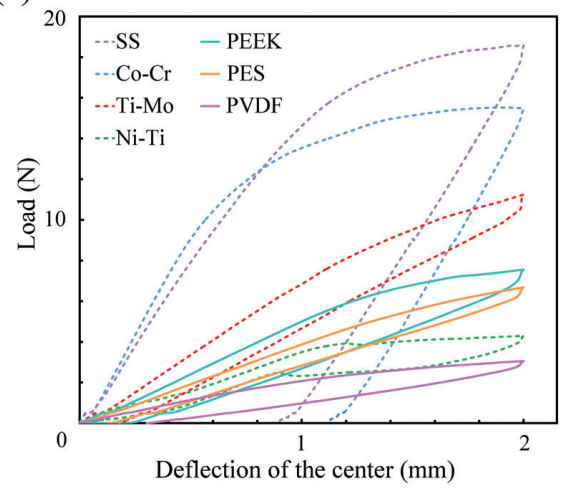

teeth at a value of $2.0 \mathrm{~mm}$ of displacement. Of the SEP wires, PEEK showed the highest flexural load. PES was comparable to PEEK. Figure 4 shows the permanent deformation of the orthodontic wires after the $2.0-\mathrm{mm}$ bending test. The Ni-Ti super-elastic wires, as expected, showed no permanent deformation, whereas SS and Co$\mathrm{Cr}$ wires were both permanently deformed by $\sim 1.0 \mathrm{~mm}$, almost half of the deflection. In contrast, the SEP wires showed less deformation (PEEK, $0.2 \mathrm{~mm}$; PES, $0.1 \mathrm{~mm}$; PVDF, $0.3 \mathrm{~mm}$ ) than all metallic wires except Ni-Ti.

As shown in Figs. $2 \mathrm{a}$ and 3 the mechanical strength (in the three-point bending test) of SEP wires at cross-sectional dimensions of $1.0 \times 1.0 \mathrm{~mm}$ square was comparable to that of Ni-Ti wire. However, the SEP wires were almost double the thickness of the metal wires $(0.40 \times 0.55 \mathrm{~mm})$, so the bending stress of each

(b)

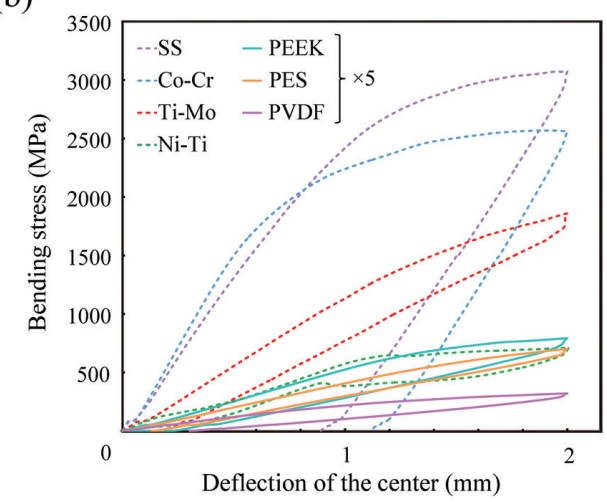

Fig. 2 Typical load-deflection curves (a) and typical bending stress-deflection curves (b) for SEP wires and commercial metallic orthodontic wires in a three-point bending test.

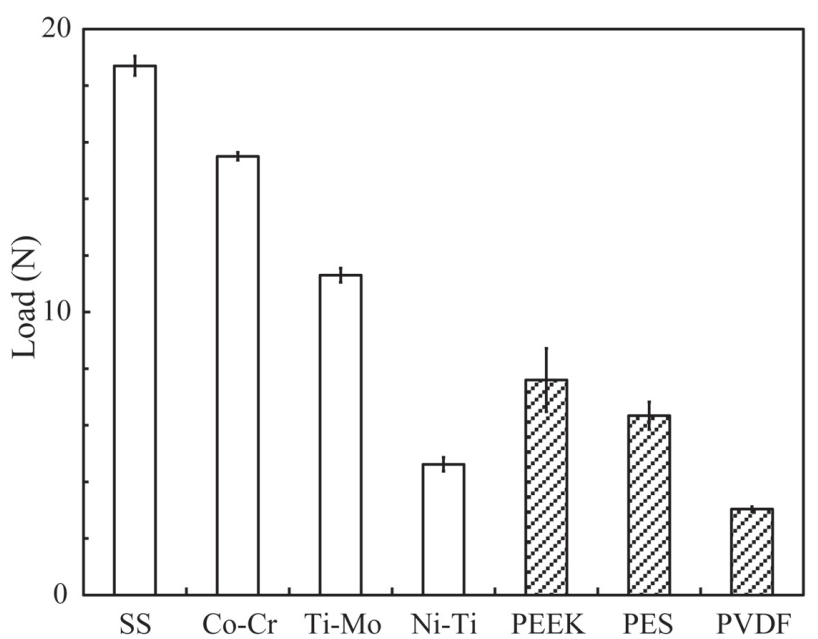

Fig. 3 Bending load at 2.0-mm deflection in the threepoint bending test.

Data are mean \pm SD from five independent replicates. Tukey-Kramer HSD test indicated significant differences between each pair $(p<0.05)$.

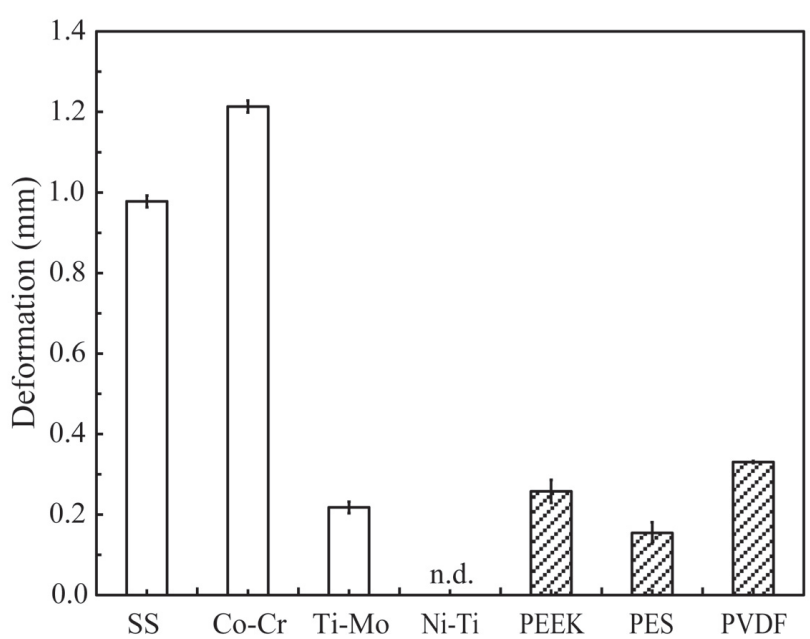

Fig. 4 Permanent deformation after three-point bending test.

Data are mean \pm SD from five independent replicates. 'n.d.' denotes 'not detected'. TukeyKramer HSD test indicated significant differences between each pair $(p<0.05)$. 
wire should also be estimated to compare the bending properties of the materials. Figure 2b shows typical bending stress-deflection curves of the wires tested. Table 2 shows the bending stress at $2.0-\mathrm{mm}$ deflection and the elastic modulus. The bending stress of the PEEK wire was almost $1 / 5$ of that of the Ni-Ti wires. Furthermore, the elastic moduli of the SEP wires were less than $1 / 12$ of those of the metal wires.

\section{Bending creep test}

Creep deformation of SEP wires after the bending creep test is shown in Fig. 5. PES and PVDF showed more than $1.0-\mathrm{mm}$ deformation after 1 month of bending at $37^{\circ} \mathrm{C}$. Deformation during the creep test was fixed at 2.0 $\mathrm{mm}$. Thus, PES and PVDF showed residual deformation of more than half the applied deformation. In contrast, PEEK experienced significantly less creep deformation than the other SEP wires.

\section{Water absorption test}

After 10 days of immersion in water at $37^{\circ} \mathrm{C}, \mathrm{PES}$ showed comparable water absorption to PMMA, whereas PEEK absorbed a much smaller amount and PVDF water absorption was negligible (Fig. 6). Even after immersion at $121^{\circ} \mathrm{C}$, the water absorption of PEEK and PVDF was less than $0.4 \mathrm{wt} \%$. These water absorption values of PEEK and PES are in good agreement with the findings from a previous study ${ }^{18}$. PVDF, a fluorocarbon polymer, is strongly hydrophobic and therefore showed no water absorption at $37^{\circ} \mathrm{C}$.

\section{DISCUSSION}

With recent concern over metal allergy and interference with MRI, there are medical reasons for developing metal-free orthodontic materials as well as the more common esthetic demands. However, non-metal orthodontic wires must have comparable mechanical strength to the metal wires and this has stymied the development of alternative materials until recently. In this study, we tested orthodontic wires fabricated from three different SEPs to determine their performance relative to metal wires and, thus, their potential as metal-free, MRI compatible, esthetic orthodontic wires.

Table 2 Values of bending stress at $2.0 \mathrm{~mm}$ deflection and elastic modulus for each tested material

\begin{tabular}{|c|c|c|c|c|c|c|c|}
\hline & SS & $\mathrm{Co}-\mathrm{Cr}$ & Ti-Mo & $\mathrm{Ni}-\mathrm{Ti}$ & PEEK & PES & PVDF \\
\hline Bending stress (MPa) & $\begin{array}{l}3,092 \\
(56.9)\end{array}$ & $\begin{array}{l}2,570 \\
(23.3)\end{array}$ & $\begin{array}{l}1,870 \\
(41.1)\end{array}$ & $\begin{array}{c}764 \\
(40.7)\end{array}$ & $\begin{array}{c}153 \\
(28.6)\end{array}$ & $\begin{array}{c}133 \\
(10.2)\end{array}$ & $\begin{array}{c}63.9 \\
(1.95)\end{array}$ \\
\hline Elastic modulus (GPa) & $\begin{array}{c}154 \\
(7.98)\end{array}$ & $\begin{array}{c}179 \\
(14.1)\end{array}$ & $\begin{array}{c}67.0 \\
(0.686)\end{array}$ & $\begin{array}{c}45.3 \\
(6.60)\end{array}$ & $\begin{array}{c}3.32 \\
(0.607)\end{array}$ & $\begin{array}{c}2.58 \\
(0.233)\end{array}$ & $\begin{array}{c}1.25 \\
(0.316)\end{array}$ \\
\hline
\end{tabular}

*Standard deviations in parentheses

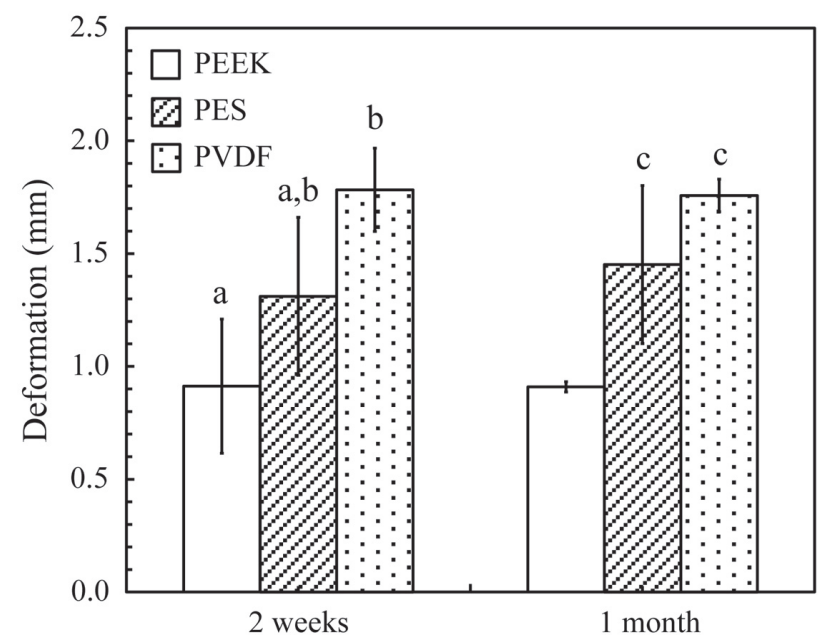

Fig. 5 Permanent deformation after 2.0-mm bending creep test (for 2 weeks and 1 month).

Data are mean \pm SD from four independent replicates. Tukey-Kramer HSD test indicated no significant differences between the bars annotated with the same letter $(p>0.05)$.

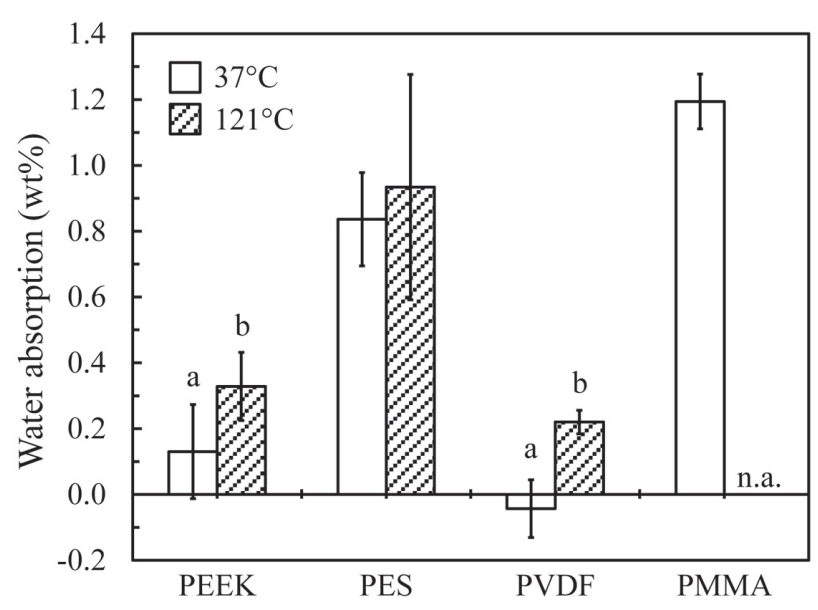

Fig. 6 Water absorption after immersion in water at $37^{\circ} \mathrm{C}$ and $121^{\circ} \mathrm{C}$ (autoclaving) for 10 days.

Data are mean \pm SD from four independent replicates. 'n.d.' denotes 'not detected', while 'n.a.' denotes 'not available'. Bars annotated with the same letter are not significantly different, as assessed by Tukey-Kramer HSD test $(p>0.05)$. 
Table 3 Comparison of relative properties of the tested SEP materials

\begin{tabular}{lcccc}
\hline & Esthetics & Bending strength & Creep resistance & Water absorption resistance \\
\hline PEEK & + & +++ & ++ & +++ \\
PES & ++ & ++ & + & - \\
PVDF & +++ & + & + & +++ \\
\hline
\end{tabular}

The SEPs were found to be able to deliver similar strength to the metal wires, but only when their thickness was increased to almost twice that of the metal wires. By replacing Ni-Ti with PEEK at identical cross-sectional geometry, the orthodontic force delivered would decrease to almost $1 / 5$ of that of Ni-Ti wire. The orthodontic force applied by $\mathrm{Ni}-\mathrm{Ti}$ is estimated to be approximately 2.0-4.0 N while recovering from $2.0 \mathrm{~mm}$ to $1.0 \mathrm{~mm}$ of bending (Fig. 2a). Extrapolation allows us to calculate that the force applied with PEEK wire with the same cross-sectional geometry $(0.40 \times 0.55 \mathrm{~mm})$ would be approximately $0.40-0.80 \mathrm{~N}$.

Various values have been suggested as the optimum orthodontic force: Schwartz ${ }^{21)}$ suggested $2.0 \cdot 10^{-3}$ $2.5 \cdot 10^{-3} \mathrm{MPa}$ (the root surface area), while Jarabak ${ }^{22}$ ) suggested 0.27-1.1 N. Thus, according to Schwartz ${ }^{21)}$, the estimated optimum force for the upper central incisor (root surface area: $2.3 \mathrm{~cm}^{2}$ ) can be calculated as 0.45-0.59 N. Therefore, the orthodontic force delivered by PEEK wire with identical cross-sectional geometry to metallic orthodontic wires $(0.40-0.80 \mathrm{~N}$ in $0.40 \times 0.55 \mathrm{~mm}$ PEEK wire) appears to be an excellent approximation of the above-mentioned optimum orthodontic force.

In the water absorption test, PEEK also performed well. Both it and PVDF absorbed minimal water, even after 10 days immersion at $121^{\circ} \mathrm{C}$, unlike PES, which underwent high water absorption, indeed close to that of PMMA. Both PEEK and PVDF are crystalline polymers whereas PES is an amorphous polymer. Generally, the water absorption of a polymer is inversely proportional to its crystallinity. In a crystalline polymer, the molecules are ordered and compacted so water molecules cannot easily penetrate. Furthermore, PVDF is a highly hydrophobic fluoropolymer, which also contributes to its low water absorption.

Table 3 shows a comparison of the various tested properties of the SEPs when used as orthodontic wire. Despite its slightly lower esthetic properties, PEEK has otherwise excellent strength and elasticity characteristics that are entirely compatible with its use in orthodontic applications. The recent development and commercialization of colored PEEK promises significant improvement in this esthetic deficit, so we conclude that PEEK has great potential as an alternative material for fabricating orthodontic wires.

\section{CONCLUSIONS}

In this study, we estimated the various properties of three types of SEP when used as orthodontic wires, with the aim of developing a novel non-metal orthodontic wire. We found that SEP wires have excellent esthetics, especially PVDF and PES but with colored PEEK materials also offering good appearance. PEEK also exhibited the highest bending strength and creep resistance and, at $1.0 \times 1.0 \mathrm{~mm}$ cross-sectional area, can deliver a similar orthodontic force to $\mathrm{Ni}$-Ti wire $(0.40 \times 0.55 \mathrm{~mm})$. In addition, PEEK and PVDF showed low water absorption. Thus, we conclude that PEEK has the optimal characteristics to be used as an esthetic metal-free orthodontic wire.

\section{ACKNOWLEDGMENTS}

The authors acknowledge Dr Mamoru OHMORI at the Institute for Materials Research, Tohoku University for support in preparing the SEP wires and Dr Masako AKIYAMA at University Research Administration Room, Research University Promotion Organization, Tokyo Medical and Dental University for statistic analysis.

\section{REFERENCES}

1) Proffit WR. Mechanical principles in orthodontic forth control. In: Proffit WR, Fields HW, Sarver DM, editors. Contemporary orthodontics. 5th ed. Missouri: Mosby Press; 2012. p. 312 318 .

2) Drake SR, Wayne DM, Powers JM, Asgar K. Mechanical properties of orthodontic wires in tension, bending, and torsion. Am J Orthod 1982; 82: 206-210.

3) Otsubo K. Development of the super-elastic Ni-Ti alloy wire appropriate to the oral environment. J Jpn Orthod Soc 1994; 53: 641-650.

4) Miura F, Mogi M, Ohura Y, Hamanaka H. The superelastic property of the Japanese NiTi alloy wire for use in orthodontics. Am J Orthod 1986; 90: 1-10.

5) Kusy RP.A review of contemporary archwires: their properties and characteristics. Angle Orthod 1997; 67: 197-207.

6) Imai H, Tanaka Y, Nomura N, Tsutsumi Y, Doi H, Kanno Z, Ohno K, Ono T, Hanawa T. Three-dimensional quantification of susceptibility artifacts from various metals in magnetic resonance images. Acta Biomater 2013; 9: 8433-8439.

7) Yamagata S, Imai T, Watari F. An experimental study of the development of an esthetic transparent orthodontic wire with fiber reinforced plastic structure. Hokkaido J Dent Sci 1995; 16: $225-244$.

8) Talass MF. Optical fibers as orthodontic archwires: optiflex. J Showa Univ Dent Soc 1995; 15: 51-58.

9) Neumann P, Bourauel C, Jäger A. Corrosion and permanent fracture resistance of coated and conventional orthodontic wires. J Mater Sci Mater Med 2002; 13: 141-147.

10) Kaphoor AA, Sundareswaran S. Aesthetic nickel titanium 
wires —how much do they deliver? Eur J Orthod 2012; 34: 603-609.

11) Burstone CJ, Liebler SAH, Goldberg AJ. Polyphenylene polymers as esthetic orthodontic archwires. Am J Orthod Dentofacial Orthop 2011; 139: e391-e398.

12) San FGB, Tekin G. A review of thermoplastic composites for bipolar plate applications. Int J Energy Res 2013; 37: 283309.

13) Katzera A, Marquardt H, Westendorf J, Wening JV. Polyetheretherketone-cytotoxicity and mutagenicity in vitro. Biomaterials 2002; 23: 1749-1759.

14) Braga FJC, Rogero SO, Couto AA, Marques RFC, Ribeiro AA, Campos JSC. Characterization of PVDF/HAP composites for medical applications. Mat Res 2007; 10: 247-251.

15) Barzin J, Madaeni SS, Mirzadeh H, Mehrabzadeh M. Effect of preparation conditions on morphology and performance of hemodialysis membranes prepared from polyether sulphone and polyvinylpyrrolidone. Iran Polym J 2005; 14: 353-360.

16) Kurtz SM, Devine JN. PEEK biomaterials in trauma, orthopedic, and spinal implants. Biomaterials 2007; 28: 48454869 .
17) Filip M, Linzer P, Strnad J. Development and clinical evaluation of bioactive implant for interbody fusion in the treatment of degenerative lumbar spine disease. In: Sakai Y, editor. Low Back Pain Pathogenesis and Treatment. Rijeka: InTech; 2012. p. 201-220

18) Baschek G, Hartwig G, Zahradnik F. Effect of water absorption in polymers at low and high temperatures. Polymer 1999; 40: 3433-3441.

19) Mitani T. Returning to the fundamentals-characteristics of plastics and evaluation. Thermal Characteristics of Plastics (in Japanese). Plastics age 1996; 42: 101-105.

20) Plastic Technology Association. In: Plastic reader (Purasuchikku tokuhon). 20th ed. Osaka: Plastic age; 2009: appendix.

21) Schwarz A M. Tissue changes incidental to orthodontic tooth movement. Int J Orthod Oral Surg 1932; 18: 331-352.

22) Jarabak J, Fizzell J. Biophysical considerations of orthodontic forces. In: Jarabak J, Fizzell J, editors. Technique and treatment with the light-wire appliances. Saint Louis: CV Mosby; 1963: 192-280. 